\title{
Article 10. Global Multilateral Benefit-sharing Mechanism
}

Parties shall consider the need for and modalities of a global multilateral benefit-sharing mechanism to address the fair and equitable sharing of benefits derived from the utilization of genetic resources and traditional knowledge associated with genetic resources that occur in transboundary situations or for which it is not possible to grant or obtain prior informed consent. The benefits shared by users of genetic resources and traditional knowledge associated with genetic resources through this mechanism shall be used to support the conservation of biological diversity and the sustainable use of its components globally.

\section{Overview}

In the context of the mainly bilateral ABs system set up by the Nagoya Protocol, Article 10 refers to the possible creation of a multilateral benefitsharing mechanism at the global level for two situations - transboundary situations or situations when it is not possible to grant or obtain PIC. To be considered as part of the exercise of national sovereignty over natural resources, ${ }^{1}$ a multilateral benefit-sharing mechanism therefore would not be intended to replace the regulation of bilateral ABs transactions supported by the Protocol ${ }^{2}$ but to supplement it. That is, it would be intended to address situations in which sovereignty is not clear ${ }^{3}$ and thus the bilateral approach

1 СвD, "Report of the Expert Meeting on Article 10 of the Nagoya Protocol on Access and Benefit-Sharing," (19 September 2013) un Doc Unep/CBD/AbSEM-A10/1/3, paragraph 3. Compare with ITPGRFA Articles 10(1) and 10(2) which state that 'In the exercise of their sovereign rights [over plant genetic resources for food and agriculture], the Contracting Parties agree to establish a multilateral system, which is efficient, effective, and transparent, both to facilitate access to plant genetic resources for food and agriculture, and to share, in a fair and equitable way, the benefits arising from the utilization of these resources, on a complementary and mutually reinforcing basis.'

2 СвD, "Report of the Expert Meeting on Article 10," UnEP/CBD/ABSEM-A10/1/3, paragraph 4.

3 Dedeurwaerdere et al., “Governing Global Scientific Research Commons," op. cit., 418.

(C) Elisa Morgera, Elsa Tsioumani, and Matthias Buck, 2015.

This is an open access chapter distributed under the terms of the Creative Commons Attribution-Noncommercial 3.0 Unported (CC-BY-NC 3.0) License. 
may not be feasible. ${ }^{4}$ Potentially, the situations covered by Article 10 could apply to 'a very large percentage of the planet's genetic resources and traditional knowledge, ${ }^{5}$ as a significant portion of genetic resources and traditional knowledge is shared by different countries.

It should be recalled from the outset that this provision was considered a compromise solution to the protracted debates during the negotiations on the scope of the Protocol. ${ }^{6}$ The African Group had proposed the idea of a 'trust fund' for sharing the benefits arising from transactions that СBD Parties could not agree to include or exclude from the temporal and spatial scope of the Protocol - namely, acquisitions before the entry into force of the Protocol, notably in ex situ collections, and acquisitions from areas beyond national jurisdiction. The African proposal was argued on the rationale that users have a moral obligation to share benefits from new and continued uses of genetic resources and traditional knowledge accessed before the entry into force of the Protocol, and that benefits could be used to contribute to conservation and sustainable use efforts. ${ }^{7}$ In the final hours of the negotiations of the Protocol, as part of its comprehensive compromise proposal, the Japanese cop Presidency introduced Article 10, which was never subject to formal negotiation.

It is noteworthy that the obligation created by Article 10 is of a purely procedural nature: it requires Parties to 'consider the need for and modalities' of a global multilateral benefit-sharing mechanism. It does not mandate Parties to establish such a mechanism and/or provide for a deadline to that end (as is the case, for instance, of the compliance procedures and mechanisms). ${ }^{8}$ It could thus be argued that nothing in this Article prevents Parties from deciding against establishing such a mechanism, although the Protocol preamble stresses that 'an innovative solution is required to address the fair and equitable sharing of benefits derived from the utilization of genetic resources and traditional knowledge associated with genetic resources that occur in transboundary situations or for which it is not possible to grant or obtain prior informed consent. ${ }^{9}$ A decision against establishing a global benefit-sharing mechanism,

4 Ibid., 417; and Maria Julia Oliva, "The Implications of the Nagoya Protocol for the Ethical Sourcing of Biodiversity," in Morgera, Buck and Tsioumani, 2010 Nagoya Protocol on Access and Benefit-Sharing in Perspective, op. cit., 381.

5 Young, “An International Cooperation Perspective," op. cit., 489.

6 Glowka and Normand, "The Nagoya Protocol on Access and Benefit-sharing," op. cit., 42-43; Elsa Tsioumani, "Access and Benefit Sharing: The Nagoya Protocol," Environmental Policy and Law 40 (2010): 288, 289. See this commentary on Article 3, section 3.

7 ENB 9/527, "Summary of the Resumed Ninth Meeting of the Working Group on ABs," 4-5.

8 See this commentary on Article 30.

9 Nagoya Protocol 13th preambular recital, emphasis added. 
however, would be politically difficult to take, as it could be considered to undermine the trust between developed and developing country Parties under the Protocol..$^{10}$ In recognition of this situation, the CBD Conference of the Parties had decided to address Article 10 at the second meeting of the Intergovernmental Committee preparing for the entry into force of the Nagoya Protocol, which convened in April 2012. ${ }^{11}$ Discussions in that forum highlighted the need for Parties to find common ground in interpreting the fairly open and laconic wording of Article 10 before making a decision on its establishment. ${ }^{12}$ An intersessional process established to that end ${ }^{13}$ attempted to explore questions raised by the provision and its linkages with other Protocol provisions in a non-negotiating setting. ${ }^{14}$ It revealed, however, continued lack of common understanding on the scope of the provision, while participants acknowledged the need to 'build trust and enhance legal certainty and transparency for the situations covered in Article 10.15 In general terms, a narrow interpretation would point to genetic resources of unknown origin found in user countries' jurisdictions, for example in their ex situ collections; while a broader interpretation would also address genetic resources collected in areas beyond national jurisdiction or the Antarctic Treaty System area. ${ }^{16}$

10 ENB 9/579, "Summary of the Second Meeting of the Intergovernmental Committee for the Nagoya Protocol," 9, where the African Group is reported to have recalled the African Group's agreement to the Nagoya Protocol with the understanding that there would be future good-faith efforts to establish the mechanism. See also Elisa Morgera, "Second Meeting of the Intergovernmental Committee for the Nagoya Protocol on Access and Benefit-Sharing: Emerging Legal Questions," Environmental Policy and Law 42 (2012): 246. СвD Decision 10/1, section B, paragraph 10.

12 ЕN $9 / 579$, "Summary of the Second Meeting of the Intergovernmental Committee for the Nagoya Protocol," 9 and 14, and Morgera, "Second Meeting of the ICnP," op. cit., 247.

13 See fn. 20 below.

14 For instance, if a Party decides to waive PIC under Article 6(1) or Article 8, could the relevant benefit-sharing obligations be met through a multilateral mechanism? And how would a multilateral mechanism be used in the case of genetic resources and traditional knowledge found in situ in transboundary areas, in view also of Article 11: see CBD, "Report of the Expert Meeting on Article 10," unep/CbD/AbSEM-A10/1/3, paragraph 4.

15 Ibid.

16 Dedeurwaerdere et al., "Governing Global Scientific Research Commons," op. cit., 418. See also ICNP, "A Report from the First Reflection Meeting on the Global Multilateral BenefitSharing Mechanism Submitted by the Fridtjof Nansen Institute," (10 January 2012) UN Doc UNEP/CBD/ICNP/2/INF/2, 7; and list of questions in CBD, "Report of the Expert Meeting," on Article 10," UnEP/CBD/ABSEM-A10/1/3, paragraph 5. As discussed in this commentary on Article 3, section 3.2 and fn. 32, for those arguing that genetic resources 
Against this background, the following sub-sections will first discuss the two situations in which a multilateral mechanism is envisaged to operate, which inform current discussions on the need for its establishment. Attention will then turn to the possible features of such a multilateral mechanism, as foreshadowed in Article 10, which will inform future discussion on the modalities of the mechanism. A brief assessment of the possible contribution of Article 10 to the holistic implementation of the Convention in the context of ABS will conclude this chapter.

\subsection{Transboundary Situations}

The first situation to which a potential multilateral benefit-sharing mechanism may apply is that of the utilization of genetic resources and of traditional knowledge associated with genetic resources ${ }^{17}$ that occur in 'transboundary situations.' The latter expression could arguably cover two instances: 'an in situ transboundary situation' in which genetic resources or traditional knowledge have developed their special characteristics and are still found across borders in natural circumstances; and 'an ex situ transboundary situation' in which genetic resources or traditional knowledge are now found outside the habitats where they developed their essential characteristics in more than one country. ${ }^{18}$ In the latter sense, it could be argued that Article 10 could cover situations in which resources are accessed in situ but then 'become' transboundary because of the need to share them among many researchers in different countries. In microbial genetic resources, for instance, taxonomic type strains are deposited in two different collections in two different countries. ${ }^{19}$ In the former sense, it remains to be clarified whether 'transboundary situations' would involve countries sharing the same ecosystem, the same species (particularly in the case of migratory species), or the same population of a species. ${ }^{20}$ A future

in areas beyond national jurisdiction are outside the scope of the Protocol, this would imply a decision to re-open the scope of the Protocol.

17 See this commentary on Article 2, section 3.

18 ICNP, "A Report from the First Reflection Meeting," UNEP/CBD/ICNP/2/INF/2, 6. Note, however, that Article 11 only refers to in situ situations.

19 Dedeurwaerdere et al., “Governing Global Scientific Research Commons," op. cit., 418-419.

20 These questions have indeed been identified bу св Parties as requiring further discussion at the second meeting of the Intergovernmental Committee for the Nagoya Protocol, which developed a roadmap for continuing discussions. The roadmap includes through Secretariat-led consultations on the basis of an indicative list of questions prepared by the Committee and the convening of an expert group to identify potential areas of 
determination by the Protocol's governing body may be needed as to whether the mere occurrence of a species in two or more countries is sufficient for Article 10 to be triggered, and whether there is a need to distinguish situations in which only the genetic resources or only the traditional knowledge associated with those specific genetic resources is transboundary. ${ }^{21}$

A well-known case of traditional knowledge in a transboundary situation is that of the San peoples' knowledge of the hunger-suppressant properties of hoodia, which was shared by San communities in South Africa, Namibia, Angola and Botswana: eventually the San tribes formed a council to negotiate a benefit-sharing agreement among themselves. ${ }^{22}$

Another question that remains to be clarified is the relationship between Article 10 and Article 11 on 'transboundary cooperation, ${ }^{23}$ which covers situations where the same genetic resources are found in situ within the territory of more than one Party, and where the same traditional knowledge associated with genetic resources is shared by indigenous and local communities found in several Parties. When discussing the global multilateral benefit-sharing mechanism, Parties may clarify whether recourse to this mechanism is alternative, or a last resort, vis-à-vis transboundary cooperation called for under Article 11. ${ }^{24}$

\subsection{Situations Where it is Not Possible to Grant or Obtain PIC}

The second instance in which the potential multilateral benefit-sharing mechanism may come into play is that of the utilization of genetic resources and traditional knowledge associated with genetic resources 'for which it is not possible to grant or obtain PIC.' This laconic provision leaves the interpreter many options open. Arguably it could cover the following situations: genetic

common understanding and areas that could be further examined for consideration by a future meeting of the Committee or the Protocol governing body at its first meeting: Recommendation 2/3, "The need for and modalities of a global multilateral benefitsharing mechanism (Article 10)," in ICNP, "Report of the second meeting," UNEP/CBD/ Cop/11/6, Annex, Part A, question 1 and Part B, questions 1-2.

ICNP, "A Report from the First Reflection Meeting," UnEP/CBD/COP/11/6, 10. As there may be significant genetic variety within species (as exemplified by the existence of subspecies, plant varieties and polymorphism), framing the discussion on species occurrence may be seen as inherently flawed: we are grateful to Geoff Burton for drawing our attention to this point.

22 Singh Nijar "An Asian Developing Country's View," op. cit., 261; and generally: Munyi and Jonas, "Implementing the Nagoya Protocol", op. cit.; and Wynberg, Schroeder and Chennells, Indigenous Peoples, Consent and Benefit Sharing, op. cit.

23 See this commentary on Article 11.

24 ICNP Recommendation 2/3, Annex, Part B, question 10. 
resources accessed prior to the entry into force of the СвD and/or the Protocol; genetic resources of unknown origin held in ex situ collections; genetic resources accessed in areas beyond national jurisdiction; publicly available traditional knowledge of unknown origin; ${ }^{25}$ or diffused traditional knowledge (traditional knowledge that is so widespread that it is no longer possible to attribute ownership to one or more indigenous and local communities). ${ }^{26}$ Other issues under discussion relate to whether it could also cover benefitsharing in cases PIC has been waived, or in the absence of a clear domestic framework on PIC. ${ }^{27}$

On the one hand, therefore, Parties will need to find agreement as to whether to interpret and operationalize Article 10 with a view to addressing certain questions related to its temporal and spatial scope that remain unclear under the Protocol, ${ }^{28}$ notably questions related to ex situ collections holding material accessed before the entry into force of the Protocol, ${ }^{29}$ materials in areas beyond national jurisdiction such as the high seas and the Area, ${ }^{30}$ and publicly available traditional knowledge. ${ }^{31}$

In view of the mechanism's complementarity to the bilateral system established by the Protocol, several Parties have indicated their concern about the

25 ICNP, "A Report from the First Reflection Meeting," UNEP/CBD/ICNP/2/INF/2, 3.

26 Singh Nijar “An Asian Developing Country's View," op. cit., 261.

27 ICNP, "A Report from the First Reflection Meeting," Unep/свD/COP/11/6, 11; and Свр, "Report of the Expert Meeting on Article 10," unep/СвD/ABSEM-A10/1/3, paragraph 4. See this commentary on Article 6, section 2.

28 ICNP Recommendation 2/3, Annex, Part A, question 2 and Part B, questions 8-9. See this commentary on Article 3, section 3.2; and Dedeurwaerdere et al, "Governing Global Scientific Research Commons," op. cit., 418.

29 With regard to ex situ collections holding material acquired before the entry into force of the свр (see this commentary on Article 3, Section 3.1), the multilateral benefit-sharing mechanism could prevent the 'chilling effect' that may derive from the exclusion of collections outside provider countries' jurisdictions from the Protocol's framework: that is, users may find it more convenient to use genetic resources in such collections rather than accessing them from a country of origin subject to the Protocol rules. Note that it has been suggested that in practice public-sector ex situ collections that do not differentiate between pre- and post-СвD/Nagoya Protocol accessions, have a 'moral duty for sharing benefits...via contributions to a funding system under Article 10': Biber-Klemm et al., "Governance options," op. cit., 225.

30 Salpin, "Law of the Sea," op. cit., 181-182, notes that 'Progress under the Protocol in regards of the global mechanism, or lack thereof, could sway discussions at the General Assembly [on marine biodiversity in areas beyond national jurisdiction, including on benefitsharing form marine genetic resources] either way.'

31 See this commentary on Article 5, section 4. 
need to ensure that any multilateral benefit-sharing mechanism does not undermine national sovereignty and would only be used when there is no real possibility to obtain PIC, ${ }^{32}$ therefore implying a requirement for due diligence by users to actively seek PIC before resorting to the multilateral mechanism. ${ }^{33}$ In addition, a question remains about how to ensure that a multilateral mechanism does not represent a disincentive for the implementation of the bilateral system of the Protocol. ${ }^{34}$ Countries may be skeptical of the need to establish any multilateral mechanism, as users may find it easier to go to a global entity than to engage in bilateral negotiations. Such recourse would have the disadvantage for provider countries that the benefits to be shared, according to the letter of the provision, would be used to support biodiversity conservation and sustainable use globally rather than to their own advantage. ${ }^{35}$

That being said, in situations where resources are shared amongst several countries or where a clear distinction between provider and user countries is not so obvious, a bilateral approach to ABS would not reward all those who have contributed to the conservation of a specific genetic resource, particularly when these have greater needs and less capacity. In these cases, a multilateral approach (especially when associated to transnational cooperation) may be more efficient than a bilateral one and the main benefits are non-monetary: there is an overall gain for all concerned Parties in working jointly towards the conservation of the same resources and sharing information about it. ${ }^{36}$

\section{Features of a Global Benefit-sharing Mechanism}

Article 10 is quite laconic about the possible feature of the multilateral benefitsharing mechanism, although the Protocol preamble indicates the need for an 'innovative' solution to the two situations identified under Article 10.37 The choice of the term 'mechanism' may exclude the creation of a 'fund', so as to allow the sharing of not only monetary but also non-monetary benefits. ${ }^{38}$ In that regard, the mechanism could serve as a platform for the

\footnotetext{
32 ICNP Recommendation 2/3, Annex, Part B, question 7.

33 See also this commentary on Article 6, section 3.

34 ICNP Recommendation 2/3, Annex, Part B, question 11.

35 See Dedeurwaerdere et al., “Governing Global Scientific Research Commons,” op. cit., 418.

36 We are grateful to Sélim Louafi for drawing our attention to this point.

37 Nagoya Protocol 13th preambular recital.

38 ICNP, “A Report from the First Reflection Meeting," UnEP/CBD/ICNP/2/INF/2, 3.
} 
exchange of information and technology transfer, as well as for the sharing of monetary benefits. ${ }^{39}$

It is also noteworthy that Article 10 focuses on 'benefits shared by users through the mechanism,' rather than by Parties or 'user countries.' It can therefore provide a specific way to operationalize the Protocol's general clause encouraging users and providers to direct benefits arising from the utilization of genetic resources towards conservation and sustainable use. ${ }^{40}$ From the perspective of the private sector, Article 10 can therefore be seen as an acknowledgement of the need for further discussion on specific, proactive tools to facilitate the operationalization of benefit-sharing in the face of complex or unclear international obligations. ${ }^{41}$ The multilateral mechanism could also create an opportunity for private companies to voluntarily apply ABs principles derived from the Protocol beyond its legal obligations. In other words, private users may decide to share benefits even if no international or domestic requirements are in place to that end, such as in the case of publicly available traditional knowledge or pre-СвD accessions, ${ }^{42}$ because of ethical, corporate accountability or marketing reasons. ${ }^{43}$

Article 10 is, on the whole, silent on the governance of the multilateral mechanism: who would be managing the mechanism and decide about the allocation of benefits? It may be expected that the Protocol's governing body would be in charge of the mechanism, but the text of the Protocol leaves it open to Parties to decide otherwise. A related question is whether contributions to the mechanism would be mandatory or voluntary. ${ }^{44}$ It has been argued that if the mechanism is established through a (formally non-binding) decision of the Protocol's governing body, the provision of benefits to the mechanism

39 Oliva, "Implications of the Nagoya Protocol," op. cit., 382. Compare with the platform for the co-development and transfer of technologies, an initiative developed in the framework of the Funding Strategy of the ITPGRFA by a group of institutions with expertise of various relevant types of technologies, for the benefit of small-scale farmers in developing countries. See ITPGRFA Governing Body, "Reports of meetings on the establishment of a platform for the co-development and transfer of technology," (24-28 September 2013) FAO Doc IT/GB-5/13/Inf.16.

$40 \quad$ See this commentary on Article 9, sections 1 and 3.

41 Oliva, "Implications of the Nagoya Protocol," op. cit., 381.

42 See this commentary on Article 6.

43 Oliva, "Implications of the Nagoya Protocol," op. cit., 381. This is indeed a question that will be considered by свD Parties: see ICN P Recommendation 2/3, Annex, Part B, question 18. ICNP Recommendation 2/3, Annex, Part B, question 17. 
would also be of a voluntary nature. ${ }^{45}$ The Protocol's governing body could, however, decide to amend the Protocol with a view to establishing a global benefit-sharing mechanism with legally binding features. Entry into force of such amendment would then require ratification by a sufficient number of Parties to the Protocol. 46

In deciding the features of the multilateral benefit-sharing mechanism, Parties may likely consider other relevant existing international processes and instruments, ${ }^{47}$ such as the benefit-sharing regime for the mineral resources in the Area, under the UN Convention on the Law of the Sea, ${ }^{48}$ or the Global Mechanism established under the UN Convention to Combat Desertification. ${ }^{49}$ The most prominent source of inspiration, however, would likely be the Multilateral System of Access and Benefit-sharing established under the ITPGRFA. ${ }^{50}$

Benefits shared under the Multilateral System include non-monetary ones, such as exchange of information, access to and transfer of technology, capacity building, as well as monetary benefits arising from commercialization. The latter is done through standard payments by the users of material accessed from the Multilateral System, according to the provisions of the standard Material Transfer Agreement, adopted by the ITPGRFA Governing Body. ${ }^{51}$ Such payments, together with voluntary donations, are directed to the Treaty's benefitsharing fund, which allocates funds under the direction of the ITPGRFA Governing Body, to particular activities designed to support farmers in developing countries conserve crop diversity in their fields, and assist farmers and

45 See Buck and Hamilton, "Nagoya Protocol," op. cit., 59; and Dedeurwaerdere et al., "Governing Global Scientific Research Commons," op. cit., 418.

46 In accordance with свD Article 29.

47 ICNP Recommendation 2/3, Annex, Part A, question 7.

48 UNCLos Part XI and 1994 Agreement: Salpin, "Law of the Sea," op. cit., 182; and Young, “An International Cooperation Perspective," op. cit., 490. See also David Kenneth Leary, International Law and the Genetic Resources of the Deep Sea (Leiden: Martinus Nijhoff, 2007), 179.

49 UN Convention to Combat Desertification in Countries Experiencing Serious Drought and/or Desertification, Particularly in Africa (Paris, 14 October 1994, in force 26 December 1996) 1954 unts 3, Article 21(4). Young, "An International Cooperation Perspective," op. cit., 490.

5o ItPgrfa Article 10. See Tsioumani, "International Treaty on Plant Genetic Resources," op. cit., 121; and Cooper, "The International Treaty on Plant Genetic Resources for Food and Agriculture," op. cit., 4. See also this commentary on Article 4, section 3.1.

51 Itpgrfa Governing Body Resolution 2/2006; smta Articles 6(7) and 6(11); and this commentary on Article 4, fn. 93. 
breeders globally adapt crops to changing needs and demands. Mandatory payments, however, seem to be taking even longer than initially expected to materialize. ${ }^{52}$ Despite two project cycles funded under the benefit-sharing fund, benefit-sharing seems to be lagging behind as a whole in comparison to facilitated access under the Multilateral System. As a result, Parties to the Treaty have recently decided to establish an intersessional process tasked to develop a range of measures that will increase user-based payments and contributions to the benefit-sharing fund in a sustainable and predictable longterm manner, as well as enhance the functioning of the Treaty's Multilateral System by additional measures. ${ }^{53}$

This recognized shortcoming in a system already operational for several years indicates that operationalization of Article 10 would be a challenging task. In addition, there are fundamental differences between the Nagoya Protocol and the International Treaty that will limit the opportunities for Parties to draw on the Multilateral System for inspiration. First of all, the ITPGRFA Multilateral System is a comprehensive system for ABS, of which the Benefitsharing Fund is only a part, and addresses one specific sector only of genetic resources. Second, the Multilateral System in effect largely consolidated the operation of a pre-existing network of research centers under the Consultative Group on International Agricultural Research (CGIAR), ${ }^{54}$ whereas the Nagoya Protocol would start from scratch. ${ }^{55}$ Third, benefits under the Multilateral System should be directed to farmers in all countries, albeit especially in developing countries and countries with economies in transition, ${ }^{56}$ whereas under the Nagoya Protocol mechanism, benefits would be directed to the conservation and sustainable use of biodiversity globally. ${ }^{57}$

See Nina I. Moeller and Clive Stannard, Identifying Benefit Flows, Studies on the Potential Monetary and Nonmonetary Benefits Arising from the International Treaty on Plant Genetic Resources for Food and Agriculture (Rome: FAO, 2013), accessed 30 November 2013, $<$ www.planttreaty.org/content/identifying-benefit-flows $>$.

ITPGRFA Governing Body Resolution 2/2013 Implementation of the Funding Strategy of the International Treaty (2013). Part IV: Terms of Reference for the Ad Hoc Open-Ended Working Group to Enhance the Functioning of the Multilateral System of Access and Benefit-Sharing.

54 Young, "An International Cooperation Perspective," op. cit., 490.

55 Ibid.

56 See itpgrfa Article 13(3).

57 Greiber et al., Explanatory Guide, op. cit., 130. See further discussion in this regard in section 4 below. 


\section{Promoting a Coherent Interpretation of the Three CвD Objectives}

As already discussed, ${ }^{58}$ the Nagoya Protocol promotes a coherent interpretation and integrative implementation of the three CBD objectives in the context of ABS. Article 10 further contributes to this end, by clearly making the objective of the global multilateral benefit-sharing mechanism that of supporting the conservation of biodiversity and the sustainable use of its components globally. If established, the multilateral fund might therefore be another source of funding and non-monetary benefits, together with the voluntary efforts of users and providers under Article 9, for the conservation and sustainable use of biodiversity. 59

It should be emphasized, however, that by making reference to 'globally,' Article 10 refrains from directing benefits to countries of origin, exclusively or specifically, which could have a 'life-changing impact' on ABs under the Protocol. ${ }^{60}$ In that regard, Parties will be well advised to ensure that the procedure for the allocation of benefits aims to recognize local contributions to conservation and sustainable use, reaching those countries and indigenous and local communities that made it possible for genetic resources and/or traditional knowledge to be used. ${ }^{61}$ In devising the allocation method, lessons learnt in the context of the ITPGRFA Multilateral System could be taken into account, including the eligibility criteria for applying for funding, and identified priorities such as the focus on smallholder farmers and climate change adaptation

$5^{8}$ See this commentary on Article 1, section 4; Article 5, section 5; Article 8, section 2; and Article 9, section 2.

59 This may possibly contribute to make the Protocol, to some extent, a type of an 'innovative financial mechanism.' Note, however, that discussion of 'innovative financial mechanisms' for biodiversity conservation and sustainable use have been very controversial in the CBD processes: for instance, СвD СОР 10 considered the creation of a 'green development fund' modelled after the Clean Development Mechanism to reward trade-certified 'land areas managed in compliance with the СвD,' in accordance with the requirements for offsets and restoration for the private sector. The proposal, however, encountered the opposition of developing countries, which wished to ensure that innovative financial mechanisms would supplement, and not replace, public funding under the CвD's financial mechanism. The other draft text on innovative financial mechanisms was withdrawn altogether during the final plenary: see EN B 9/544, "Summary of the Tenth Conference of the Parties to the Convention on Biological Diversity," 13. See comments in Morgera and Tsioumani, "Yesterday, Today, and Tomorrow," op. cit., 26-29. In the absence of a definition, it can be argued that the expression 'innovative financial mechanism' only applies to market-based mechanisms.

$60 \quad$ Young, "An International Cooperation Perspective," op. cit., 489-90.

61 Oliva, "Implications of the Nagoya Protocol," op. cit., 382. 
needs. ${ }^{62}$ That being said, there appears to be limitations to the project-based approach currently followed by the Treaty, which may be seen as introducing a competitive logic into a global cooperative framework and which may not be necessarily effective in fulfilling benefit-sharing expectations at national and local levels. ${ }^{63}$ Attention would therefore be drawn on devising a global mechanism that is inclusive and does not disadvantage stakeholders who are less equipped to obtain the benefits generated at the global level. ${ }^{64}$

62 ICNP, "A Report from the First Reflection Meeting," UnEP/CBD/ICNP $/ 2 / \operatorname{INF} / 2$, 14. For information on the ITPGRFA benefit-sharing fund, see "The Benefit-Sharing Fund," ITPGRFA, accessed 30 November 2013, <www.planttreaty.org/content/benefit-sharingfund $>$. The list of projects approved under the first project cycle, see: "Projects under the Benefit-Sharing Fund (2009-2011) - 1st Call," ITPGRFA, accessed 30 November 2013, $<$ www.planttreaty.org/content/projects-2009-2011>; and under the second one: "Call for Proposals 2010-2011," ITPGRFA, accessed 30 November 2013, <www.planttreaty.org/ content/call-proposals-2010-2011>.

63 Sélim Louafi, "Reflections on the Resource Allocation Strategy of the Benefit Sharing Fund" (paper for the fifth meeting of the Governing Body of the International Treaty on Plant Genetic Resources for Food and Agriculture; Bern: Swiss Federal Office for Agriculture, 2013).

64 We are grateful to Sélim Louafi for drawing our attention to this point. 